\title{
Links between Biomass of (Cremastra Appendiculata) Roots Cuticle and Daily Solar Radiation by Big Data of Long-Time Wild Investigation in Mei County
}

\section{Bing-Hua Liao*}

The Key Laboratory of Ecological Restoration in Hilly Areas, Forestry Department of Henan Province, Institute of chemistry and environmental engineering, Ping-ding-shan University, Ping-ding-shan City, 467000, China. Institute of life and science, Henan University, Kai-feng City, He-nan Province, 475004, China

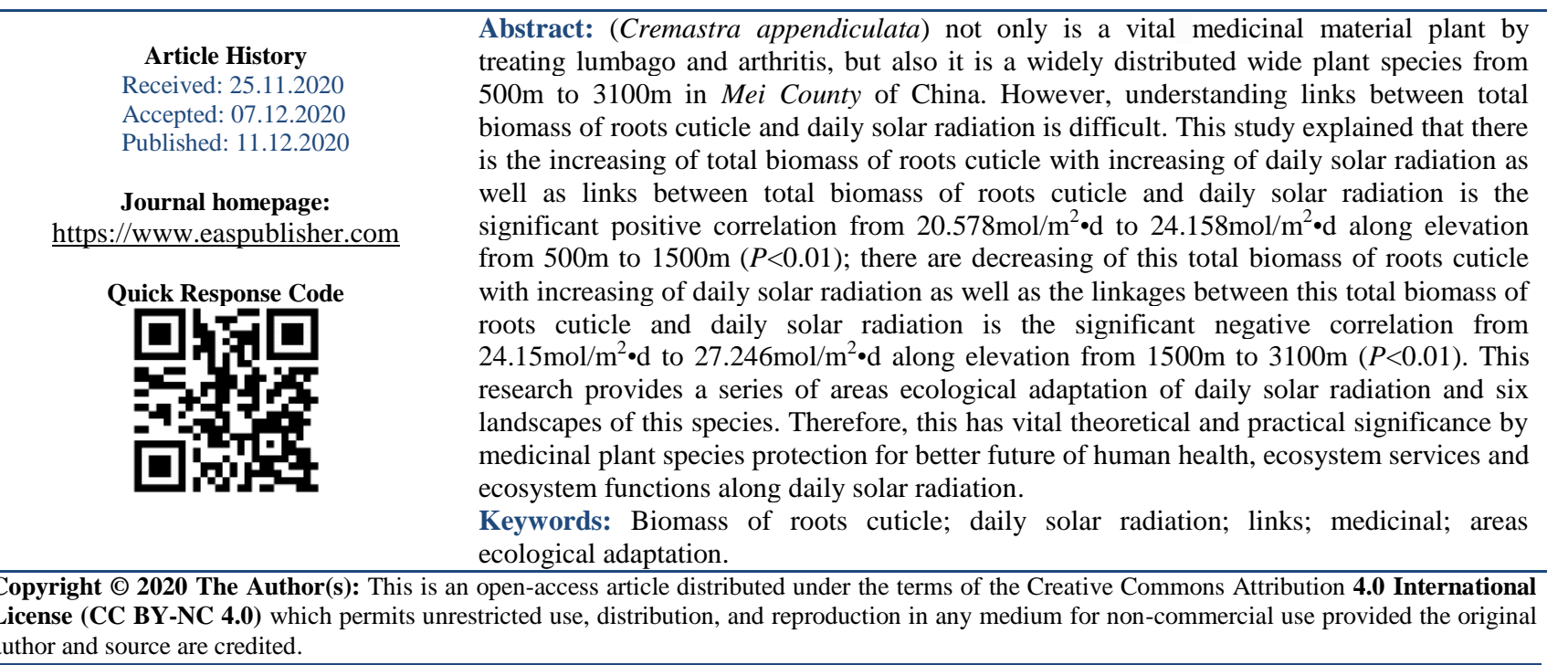

\section{INTRODUCTION}

More and more researches have assessed the links between total biomass of roots cuticle of medical plants and environments along elevation from total biomass of plant roots cuticle (plant functional groups, biodiversity, height, total biomass of roots cuticle) of medicinal plant species perspective by biodiversity researches (Table 1) [1-11], which based on better future of human heath by the finding medicinal plants. However, traditional medicinal plant species with typical history spanning over 1500 years, as well as areas ecological adaptation of a lot of total biomass of roots cuticle of plant are unknown and values of medicinal species also cannot be utilized [12-16].

(Cremastra appendiculata) not only is a vital medicinal material plant of treating lumbago and arthritis, but also it is widely distributed wide specie along elevation from 500 to $3100 \mathrm{~m}$ by "big data" of our long-time investigation in Mei County. This species is belonging to Cremastra genus of Orchidaceae families of Monocotyledoneae in Angiospermae. However, understanding the links between total biomass of roots cuticle of medical plants and dynamics of daily solar radiation along elevation is unknown, as well as the links between total biomass of roots cuticle of plants and daily solar radiation is difficult finding along elevation and environmental factors [1-17].

Meanwhile, elevation and environmental (daily solar radiation, disturbances) gradient also influence on total biomass of roots cuticle (biomass, biodiversity, structure, et al.) of plant species in "big data" investigation of our long years researches Understanding these medical values of medicinal spices and the links between total biomass of roots cuticle of medicinal plant and the daily solar radiation and different areas ecological adaptation of medical plants is a vital rule. 
Table-1: Evaluation of links between dynamics of medicinal plants and environmental factors

\begin{tabular}{|c|c|}
\hline Assessments of links between multilevel medicinal plant and elevation & \multicolumn{1}{|c|}{ Authors } \\
\hline Links between biodiversity of plant functional groups and elevation at STEDS. & Liao, et al., 2010[1]. \\
\hline Links between biomass of medicinal herbs and elevation in wetland landscape. & Liao, et al., 2011a [2]. \\
\hline Links between plant functional groups diversity and elevation in forest. & Liao, et al., 2011b [3]. \\
\hline Links between plant functional groups and elevation in near-natural forests. & Liao, et al., 2014a [4]. \\
\hline Links between biodiversity and disturbance of different elevation in wetland. & Chen, et al., 2019[5]. \\
\hline Links between number of medicinal tree species and elevation in forestation. & Liao, et al., 2019a [6]. \\
\hline Links between medicinal tree trunk volume and elevation in forest landscape. & Liao, et al., 2019b [7]. \\
\hline Links between average height of medicinal tree and elevation in landscapes. & Liao, et al., 2019c [8]. \\
\hline Links between number of tree community crown volume and elevation. & Liao, et al., 2019d [9]. \\
\hline Links between number of tree individual specie's crown volumes and elevation. & Liao, et al., 2019e[10] \\
\hline Links between diversity of herbs and different disturbance of different elevation. & Liao, 2014 b[11]. \\
\hline
\end{tabular}

Therefore, there is not only the vital links between total biomass of roots cuticle of species and daily solar radiation, but also there is a series of (good, better, best) this species areas ecological adaptation of daily solar radiation in six near-natural ecosystem for the better future of ecosystem composition (services, functions, structures) and human health along the different elevation and environments at the spatialtemporal-environmental-disturbance scales (STEDS).

\section{Environmental condition, situation of special} vegetation and methods of research

Research typical area is local in three vegetation zones in China: firstly, evergreen vegetation in north subtropical zone; secondly, evergreen and deciduous coniferous and broad-leaved mixed forest in north subtropical and warm temperate transition; thirdly, deciduous vegetation in warm temperate zone by large total biomass of roots cuticle investigation of medicinal plant. Thus, our research area is local in evergreen and deciduous coniferous and broad-leaved mixed forest in north subtropical and warm temperate transition (landscape types included: urban, rural settlement, wetland, forest, grassland, farmland, river landscape as well as mixed zone landscape interaction each other) along elevation and environmental gradient in Mei County of China (Figure 1).
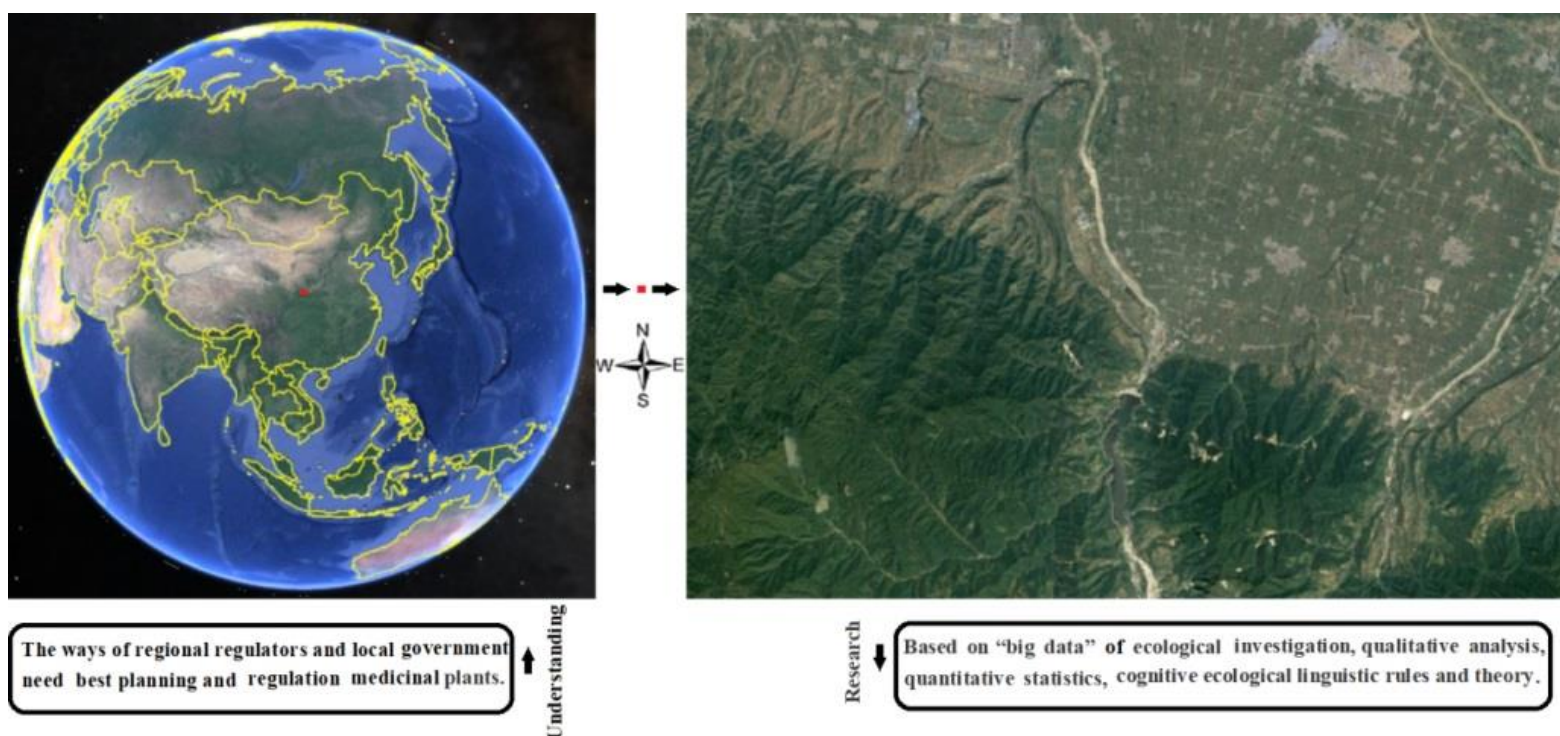

ป

Based on "big data" of ecological investigation, qualitative analysis quantitative statistics, cognitive ecological linguistic rules and theory.

Links between Biomass of (Cremastra appendiculata) Roots Cuticle and Daily Solar Radiation

Fig-1: A Digital Cadaster Map and Research Methods of Typical Location in Mei County of China of Earth

There is a long time investigation by the links between medicinal plant species diversity and environments from 2005 to 2019. Investigation "big data" included that dynamics of total biomass of roots cuticle of medicinal plants or other index along environments (Fu-niu Mountain, Yellow River, Ye County, Yi-luo River, Bai-gui Lake, et al.) based on ecological cognitive ability [2-15].
Thus, there is the links between total biomass of (Cremastra appendiculata) roots cuticle and daily solar radiation as well as there is a series of (good, better, best) natural landscapes areas ecological adaptation of daily solar radiation of this medical plant species by the "big data" of the ecological investigation, qualitative analysis, quantitative statistics, human cognitive ecological linguistic rules, theories, methods 
and ways along elevation and environmental gradient [3-19].

Results based on quantitative statistics and qualitative analysis

(Cremastra appendiculata) not only is a vital medicinal material plant of treating lumbago and arthritis, but also it is widely distributed wide plant species along elevation from 500 to $3100 \mathrm{~m}$ in natural ecosyleaves along elevation from $500 \mathrm{~m}$ to $3100 \mathrm{~m}$ in Mei County. However, understanding daily solar radiation effect on the links between this total biomass of roots cuticle and daily solar radiation is very difficult. Using "big data" investigation, this research suggested there are three rules along increasing of daily solar radiation and elevation gradient in Mei County of China:

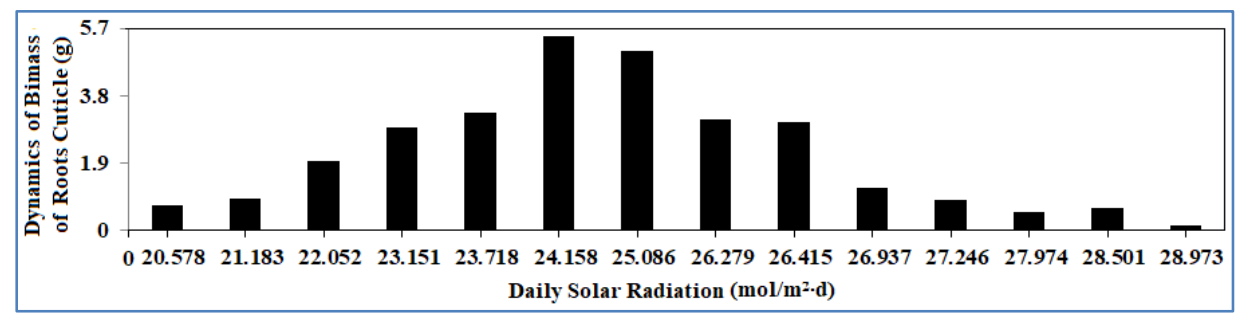

Fig-2: Dynamics of Biomass of Roots Cuticle along Daily Solar Radiation Gradient

Firstly, this research proposed that not only there is the increasing of total biomass of roots cuticle of this plant species with the increasing daily solar radiation, and there is the significant positive correlation between total biomass of roots cuticle of this species and daily solar radiation from $20.578 \mathrm{~mol} / \mathrm{m}^{2} \cdot \mathrm{d}$ to $24.158 \mathrm{~mol} / \mathrm{m}^{2} \cdot \mathrm{d}(P<0.01)$ along elevation from $500 \mathrm{~m}$ to $1500 \mathrm{~m}$, but also there is the decreasing of total biomass of roots cuticle of this plant species with the increasing of daily solar radiation, as well as there is the significant negative correlation between total biomass of roots cuticle of this plant species and daily solar radiation from $24.158 \mathrm{~mol} / \mathrm{m}^{2} \cdot \mathrm{d}$ to $28.973 \mathrm{~mol} / \mathrm{m}^{2} \cdot \mathrm{d}$ $(P<0.01)$ along elevation from $1500 \mathrm{~m}$ to $3100 \mathrm{~m}$. Because there is the increasing of daily solar radiation with increasing daily solar radiation and elevation is the significant positive correlation along elevation from 500m to $3100 \mathrm{~m}(P<0.01)$ (Figure 2, 3; Table 2, 3).

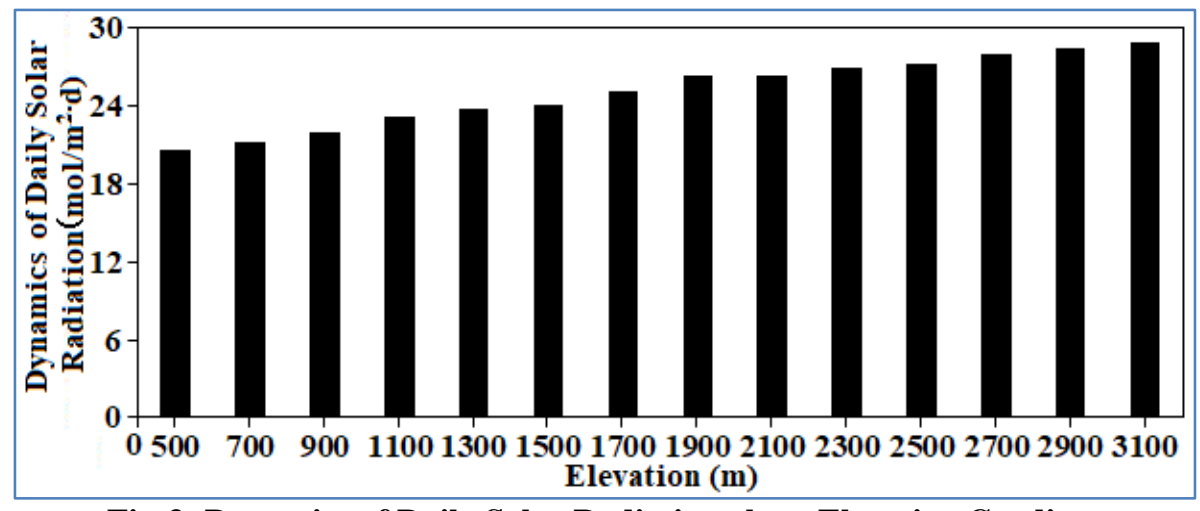

Fig-3: Dynamics of Daily Solar Radiation along Elevation Gradient

Secondly, this research provided good areas ecological adaptation of daily solar radiation of this medical plant species is local in the areas ecological adaptation of daily solar radiation from $20.578 \mathrm{~mol} / \mathrm{m}^{2} \cdot \mathrm{d}$ to $28.973 \mathrm{~mol} / \mathrm{m}^{2} \cdot \mathrm{d}$ along elevation from $500 \mathrm{~m}$ to $3100 \mathrm{~m}$, and not only there are better areas ecological adaptation of daily solar radiation of this species from
$23.151 \mathrm{~mol} / \mathrm{m}^{2} \cdot \mathrm{d}$ to $27.974 \mathrm{~mol} / \mathrm{m}^{2} \cdot \mathrm{d}$ along elevation gradient from $1100 \mathrm{~m}$ to $2700 \mathrm{~m}$, but also there are the best areas ecological adaptation of daily solar radiation of this medical plant species from $23.718 \mathrm{~mol} / \mathrm{m}^{2} \cdot \mathrm{d}$ to $25.086 \mathrm{~mol} / \mathrm{m}^{2} \cdot \mathrm{d}$ along elevation from $1300 \mathrm{~m}$ to $1700 \mathrm{~m}$ at STEDS in Mei County (Figure 2,3).

Table-2: Correlation between Total Biomass of Roots cuticle and Daily Solar Radiation

\begin{tabular}{|c|c|}
\hline Daily Solar Radiation along Elevation Gradient & Plant Biomass of Roots cuticle \\
\hline Daily Solar Radiation From 500m to $1500 \mathrm{~m}$ & $0.944^{* *}$ \\
\hline Daily Solar Radiation From $150 \mathrm{~m}$ to $3100 \mathrm{~m}$ & $-0.958^{* *}$ \\
\hline \multicolumn{2}{|c|}{ Note: ${ }^{*}, P<0.05 ; * *, P<0.01$. } \\
\hline
\end{tabular}


Thirdly, this research suggested that medicinal plant (Cremastra appendiculata) of treating lumbago and arthritis is local in six natural landscape types (forest, mixed between grassland and forest, mixed between forest and wetland, mixed between forest and river, mixed between forest and urban, mixed between forest and rural settlement), because of there is result of dynamics of air and soil environments along elevation and environmental gradient at "big data" STEDS (Figure1).

Table-3: Correlation between Total Biomass of Roots cuticles Daily Solar Radiation Gradient

\begin{tabular}{|c|c|}
\hline Elevation (m) & Elevation Gradient from 500m to $3100 m$ \\
\hline Daily Solar Radiation & $0.992 * *$ \\
\hline & Note: ${ }^{* *}, P<0.01$.
\end{tabular}

This work finds a series of typical (good, better, best) areas ecological adaptation of (Cremastra appendiculata) of treating lumbago and arthritis along elevation (daily solar radiation), and there is links between total biomass of roots cuticle and daily solar radiation along elevation.

In short, regional planners need regulation a lot of landscape sustainability based on researches on total biomass of roots cuticle of medical plant species (biodiversity, composition, structure, et al.) by the "big data" investigation, qualitative analysis, quantitative statistics, human cognitive ecological linguistic rules and theory of the links between biodiversity and environments in the global, local, regional landscapes for the better future of human health and ecosystem stability (functions, structures, services) and human health along elevation, daily solar radiation [1-15, 2644].

\section{Conclusion AND Discussion}

Understanding the dynamics of total biomass of roots cuticle of medicinal species is very difficult [225]. This research suggested three rules with biomass of roots cuticle of this species:

Firstly, there is the significant positive correlation between total biomass of roots cuticle of this species and daily solar radiation along elevation from $500 \mathrm{~m}$ to $1500 \mathrm{~m}(P<0.01)$, because of there is increasing of total biomass of roots cuticle with increasing of daily solar radiation from $20.578 \mathrm{~mol} / \mathrm{m}^{2} \cdot \mathrm{d}$ to $24.158 \mathrm{~mol} / \mathrm{m}^{2} \cdot \mathrm{d}$. Meanwhile, there is significant negative correlation between Total biomass of roots cuticle and daily solar radiation along elevation from along elevation from $1500 \mathrm{~m}$ to $3100 \mathrm{~m} \quad(P<0.01)$, because of there is decreasing of total biomass of roots cuticle with increasing of daily solar radiation from $24.158 \mathrm{~mol} / \mathrm{m}^{2} \cdot \mathrm{d}$ to $27.246 \mathrm{~mol} / \mathrm{m}^{2} \bullet \mathrm{d}(P<0.01)$.

Secondly, this research provided good areas ecological adaptation along elevation from 500 to $3100 \mathrm{~m}$, the better areas ecological adaptation along elevation from 1100 to $2500 \mathrm{~m}$, and the best areas ecological adaptation of daily solar radiation of this medical plant along elevation from 1300 to $1700 \mathrm{~m}$ is local in Mei County of China along environmental gradient at STEDS (Figure 2, 3).

Thirdly, this research suggested that total biomass of roots cuticle of this species of treating lumbago and arthritis is local in six near-landscape types (forests, mixed landscapes between forestation and wetland, mixed landscapes between grassland and forestation, mixed landscapes between forest and urban, mixed landscapes between forest and river, mixed landscapes between forest and rural settlement) by "big data" and researches along air and soil environments (Figure1).

Therefore, this research has a vital theoretical and practical significance for the reasonable protection of total biomass of roots cuticle of this species along the daily solar radiation and elevation gradient in six natural landscapes. Because of this plant species not only is a vital widely distributed wide medicinal plant species of treating lumbago and arthritis, but also there are three rules by the links between total biomass of roots cuticle of this species and daily solar radiation.

Abbreviation: STEDS, the spatial-temporalenvironmental-disturbance scales.

\section{ACKNOWLEDGEMENT}

This work was supported by A Grade of Key Disciplines of Environmental Science Foundation, B Grade of Key Disciplines of Mistrials Science of PingDing-shan University in China; Science and Technology Department of He'nan Province Foundation (KJT-17202310242; 092102110165); Subprojects by Intergovernmental Platform on Biodiversity and Ecosystem Services (IPBES); and better ideas of researchers of "1st Biotechnology World Congress" in 2011, "2st Biotechnology World Congress" in 2012, "3st Biotechnology World Congress" in 2013 is appreciated.

\section{REFERENCES}

1. Liao, B. H., \& Wang, X. H. (2010). Plant functional group classifications and a generalized hierarchical framework of plant functional traits. African Journal of Biotechnology, 9(54), 
9208-9213.

2. Liao, B. H., Ding, S. Y., Liang, G. F., Guo, Y. L., Tian, L., Shu, S., ... \& Hu, H. X. (2011). Dynamics of plant functional groups composition along environmental gradients in the typical area of YiLuo River watershed. African Journal of Biotechnology, 10(65), 14485-14492.

3. Liao, B. H., Ding, S. Y., Hu, N., Gu, Y. F., Lu, X. L., Liang, G. F., ... \& Ding, S. (2011). Dynamics of environmental gradients on plant functional groups composition on the northern slope of the Fu-Niu Mountain Nature Reserve. African Journal of Biotechnology, 10(82), 18939-18947.

4. Liao, B. H., Liu, Q. F., \& Lu, D. (2014). Dynamics of environmental gradients on plant functional groups composition species in near-natural community ecological restoration on the southern slope of the Fu-Niu Mountain Nature Reserve. Journal of Science, 4(5), 306-312.

5. Chen, H.S., Liao, B.H. (2019). Research on risk assessment and early warning mechanism of agricul -tural non-point source pollution in Bai-gui Lake watershed by GIS. International Journal of Pharmacognosy and Pharmaceutical Sciences, 1:25-29.

6. Liao, B. H., Liu, Y. P., Zuo, H., Kong, Y. Y., Jiang, C. G., Xia, J. R., ... \& Xu, Y. L. (2019). Dynamics of 18 (Sophora Japonica) Tree Individual Trunk Volume along Elevation Gradient in Ye County. Trees, 2000, 724.

7. Liao, B. H., Liu, Y. P., Zuo, H., Kong, Y. Y., Jiang, C. G., Xia, J. R., ... \& Xu, Y. L. (2019). Dynamics of 18 (Sophora Japonica) Tree Individual Trunk Volume along Elevation Gradient in $\mathrm{Ye}$ County. Trees, 2000, 724.

8. Liao, B. H., Liu, Y. P., \& Zuo, H. (2019). Elevation Dynamics of (Sophora japonica) Community's Height in Ye County. International Journal of Research Pharmaceutical and Nano Sciences, 8(1).

9. Liao, B., Liu, Y., Zuo, H., Xia, J., Yu, Z., Song, C., ... \& Xu, Y. (2019). Dynamics of 18 (Sophora japonica) Tree Community's Crown Volume along Elevation Gradient in Ye County. Open Journal of Ecology, 9(7), 209-215.

10. Liao, B.H., Liu, Y.P. (2019). Dynamics of 18 (Sophora japonica) Tree Individual Specie's Crown Volume along Elevation Gradient in $\mathrm{Ye}$ County. International Journal of Research Pharmaceutical and Nano Sciences, 8:62-68.

11. Liao, B.H. (2014). A new model of dynamic of plant diversity in changing farmlands, implications for the management of plant biodiversity along differential environmental gradient in the spring. African Journal of Environmental Science and Technology, 8:171- 177.

12. Zhu, D. M., \& Liao, B. H. (2015). A dynamical system of human cognitive linguistic theory in learning and teaching of the typical university in Henan Province. International Journal of Pharmacy \& Therapeutics, 6, 4-6.
13. Jin, D., Dai, K., Xie, Z., \& Chen, J. (2020). Secondary Metabolites Profiled in Cannabis Inflorescences, Leaves, Stem Barks, and Roots for Medicinal Purposes. Scientific reports, 10(1), 1-14.

14. Yang, Y., Sun, M., Li, S., Chen, Q., da Silva, J. A. T., Wang, A., ... \& Wang, L. (2020). Germplasm resources and genetic breeding of Paeonia: a systematic review. Horticulture Research, 7(1), 119.

15. Lyubchyk, S., Shapovalova, O., Lygina, O., Oliveira, M. C., Appazov, N., Lyubchyk, A., ... \& Pombeiro, A. J. (2019). Integrated Green Chemical Approach to the Medicinal Plant Carpobrotus edulis Processing. Scientific Reports, 9(1), 1-12.

16. Köberl, M., Erschen, S., Etemadi, M., White, R. A., El-Arabi, T. F., \& Berg, G. (2019). Deciphering the microbiome shift during fermentation of medicinal plants. Scientific reports, 9(1), 1-11.

17. Schultz, F., Anywar, G., Tang, H., Chassagne, F., Lyles, J. T., Garbe, L. A., \& Quave, C. L. (2020). Targeting ESKAPE pathogens with anti-infective medicinal plants from the greater Mpigi region in Uganda. Scientific reports, 10(1), 1-19.

18. Mohanraj, K., Karthikeyan, B. S., Vivek-Ananth, R. P., Chand, R. B., Aparna, S. R., Mangalapandi, P., \& Samal, A. (2017). IMPPAT: A curated database of Indian medicinal plants, phytochemistry and therapeutics. bioRxiv, 206995.

19. MacDougall, A. S., McCann, K. S., Gellner, G., \& Turkington, R. (2013). Diversity loss with persistent human disturbance increases vulnerability to ecosystem collapse. Nature, 494(7435), 86-89.

20. Izuishi, Y., Isaka, N., Li, H., Nakanishi, K., Kageyama, J., Ishikawa, K., ... \& Yazaki, K. (2020). Apple latent spherical virus (ALSV)induced gene silencing in a medicinal plant, Lithospermum erythrorhizon. Scientific reports, 10(1), 1-9.

21. Saeed, S., Ali, H., Khan, T., Kayani, W., \& Khan, M. A. (2017). Impacts of methyl jasmonate and phenyl acetic acid on biomass accumulation and antioxidant potential in adventitious roots of Ajuga bracteosa Wall ex Benth., a high valued endangered medicinal plant. Physiology and molecular biology of plants, 23(1), 229-237.

22. Noel, J. P. (2010). Synthetic metabolism goes green. Nature, 468(7322), 380-381.

23. Ibisch, P. L., Jennings, M. D., \& Kreft, S. (2005). Biodiversity needs the help of global change managers, not museumkeepers. Nature, 438(7065), 156-156.

24. Rukh, G., Ahmad, N., Rab, A., Ahmad, N., Fazal, H., Akbar, F., ... \& Samad, N. (2019). Photodependent somatic embryogenesis from nonembryogenic calli and its polyphenolics content in high-valued medicinal plant of Ajuga bracteosa. Journal of Photochemistry and Photobiology B: Biology, 190, 59-65.

25. Das, A., Kamal, S., Shakil, N. A., Sherameti, I., 
Oelmüller, R., Dua, M., ... \& Varma, A. (2012). The root endophyte fungus Piriformospora indica leads to early flowering, higher biomass and altered secondary metabolites of the medicinal plant, Coleus forskohlii. Plant signaling \& behavior, 7(1), 103-112.

26. Lombardo, U., Iriarte, J., Hilbert, L., Ruiz-Pérez, J., Capriles, J. M., \& Veit, H. (2020). Early Holocene crop cultivation and landscape modification in Amazonia. Nature, 581(7807), 190-193.

27. Singh, S. P., \& Gaur, R. (2016). Evaluation of antagonistic and plant growth promoting activities of chitinolytic endophytic actinomycetes associated with medicinal plants against Sclerotium rolfsii in chickpea. Journal of Applied Microbiology, 121(2), 506-518.

28. Hartt, L. (2005). Biodiversity: saving Florida panther makes sense. Nature, 438(7065), 156-157.

29. Larsen, H. O. (2002). Commercial medicinal plant extraction in the hills of Nepal: local management system and ecological sustainability. Environmental management,29(1), 88-101.

30. Ali, H., Khan, M. A., Kayani, W. K., Dilshad, E., Rani, R., \& Khan, R. S. (2019). Production of biomass and medicinal metabolites through adventitious roots in Ajuga bracteosa under different spectral lights. Journal of Photochemistry and Photobiology B: Biology, 193, 109-117.

31. Renner, S. C. (2005). Biodiversity: there's a role to be played by 'museum-keepers' too. Nature, 438(7070), 914-914.

32. Das, K., Dang, R., Shivananda, T. N., \& Sur, P. (2005). Interaction between phosphorus and zinc on the biomass yield and yield attributes of the medicinal plant stevia (Stevia rebaudiana). TheScientificWorldJournal, 5.

33. Cotto, O., Wessely, J., Georges, D., Klonner, G., Schmid, M., Dullinger, S., ... \& Guillaume, F. (2017). A dynamic eco-evolutionary model predicts slow response of alpine plants to climate warming. Nature Communications, 8(1), 1-9.

34. Opgenoorth, L., Hotes, S., \& Mooney, H. (2014). Biodiversity panel should play by rules. Nature, 506(7487), 159-159.

35. Igor, V., Jayanth, R.B. (2004). The stability of forest biodiversity. Nature, 427: 696-697.

36. Song, H., Payne, S. (2009). Spatiotemporal modulation of biodiversity in a synthetic chemicalmediated ecosystem. Nature Chemical Biology, 5: 929-935.

37. Waldron, A., Miller, D.C. (2017). Reductions in global biodiversity loss predicted rom conservation spending. Nature, 551:364-367.

38. Elkins, A.C., Deseo, M.A. (2019). Development of a validated method for the qualitative and quantitative analysis of cannabinoids in plant biomass and medicinal cannabis resin extracts obtained by super-critical fluid extraction. Journal of Chromatography B, 1109:76-83.

39. Kenneth, G.C., Patricio, G. (2020). A global perspective on sustainable intensification research. Nature Sustainability, 3:262-268.

40. Grass, I., Kubitza, C. (2020). Trade-offs between multifunctionality and profit in tropical small hoder landscapes. Nature Communications, 11:113.

41. Harris, J., Kotiaho, J.S. (2018). New jargon seeping slowly into biodiversity world. Nature, 562:39.

42. Kumar, V., Roy, B.K. (2018). Population authentication of the traditional medicinal plant Cassia tora $L$. based on ISSR markers and FTIR analysis. Scientific Reports, 8:1-11.

43. Jacquelie, O., Bernhard, S. (2020). Terrestrial landcover type richness is positively linked to landscape level functioning. Nature Communications, 11:1-10.

44. Liao, Georgina, M.M. (2019). Limits to agricultural land for retaining acceptable levels of local biodiversity. Nature Sustainability, 2: 491498. 